Mycologia, 103(3), 2011, pp. 458-465. DOI: 10.3852/10-121

(C) 2011 by The Mycological Society of America, Lawrence, KS 66044-8897

\title{
Ethanolic and aqueous extracts derived from Australian fungi inhibit cancer cell growth in vitro
}

\author{
Karren D. Beattie ${ }^{1}$ \\ Rahel Ulrich ${ }^{1}$ \\ School of Pharmacy, Griffith University, Gold Coast \\ campus, Queensland 4222, Australia
}

\section{Darren Grice \\ Institute for Glycomics, Griffith University, Gold Coast campus, Queensland 4222, Australia}

Shaikh J. Uddin

Tony B. Blake

Kyle A. Wood

Jules Steele

Fontaine Iu

School of Pharmacy, Griffith University, Gold Coast campus, Queensland 4222, Australia

Tom W. May

Royal Botanic Gardens Melbourne, South Yarra 3141, Australia

Evelin Tiralongo ${ }^{2}$

School of Pharmacy and Griffith Health Institute, Griffith University, Gold Coast campus, Queensland 4222, Australia

Abstract: Fifteen Australian macrofungi were investigated for cytotoxic activity. Ethanol, cold and hot water extracts of each species were screened for cytotoxic activity against normal mouse fibroblast cells (NIH/3T3), healthy human epithelial kidney cells (HEK-293), four cancer cell lines, gastric adenocarcinoma cells (AGS), two mammary gland adenocarcinoma cells (MDA-MB-231, MCF7) and colorectal adenocarcinoma cells (HT-29) with a validated MTT assay. Most extracts derived from Omphalotus nidiformis, Cordyceps cranstounii and Cordyceps gunnii demonstrated significant cytotoxic activity toward a variety of cancer cell lines. In contrast only some extracts from Coprinus comatus, Cordyceps hawkesii, Hypholoma fasciculare, Lepista nuda, Leratiomyces ceres and Ophiocordyceps robertsii displayed significant cytotoxic activity, which was usually selective for only one or two cancer cell lines tested. The least cytotoxic species evaluated in this study were Agaricus bitorquis, Coprinopsis atrametaria, Psathyrella asperospora, Rus-

\footnotetext{
Submitted 22 Apr 2010; accepted for publication 14 Nov 2010.

${ }^{1}$ Authors contributed equally.

${ }^{2}$ Corresponding author. E-mail: E.Tiralongo@griffith.edu.au; Phone: ++61 75552 7098; Fax: ++61 755528804
}

sula clelandii, Tricholoma sp. AU2 and Xerula mundroola.

Key words: bioactivity, Coprinus, Cordyceps, cytotoxic, drug discovery, Hypholoma, Lepista, Leratiomyces, macrofungi, Omphalotus, Ophiocordyceps

\section{INTRODUCTION}

The medicinal use of fungi has been documented in China, Russia, Japan and Korea, as well as in the United States and Canada (Wasser and Weis 1999). For example entire fungi and fungi extracts are used in traditional Chinese medicine for the treatment of cancer (Dong 2001, Huang 2007, Xu 2003, Zhang 2002, Zhu and Wei 2000), and these fungi preparations as well as isolated fungal fractions and compounds are used as adjuvants to surgery, radiotherapy or chemotherapy (Lindequist et al. 2005). Lentinan, derived from Lentinula edodes, schizophyllan from Schizophyllum commune, the Maitake D-fraction ( $\beta$ glucan) from Grifola frondosa and krestin from Trametes versicolor (synonym Coriolus versicolor), are in clinical use for this purpose. Moreover mushroom consumption has been shown to prevent the development of cancer later in life with studies reporting an inverse correlation between mushroom intake and the risk of developing gastric (Kim et al. 2002) or breast cancer (Zhang et al. 2009).

This anti-cancer activity has been attributed partially to the polysaccharides present in basidiomycetes, which are high molecular weight carbohydrate polymers (ca. 500-2000 kDa) and arise as constituents of the fungal cell wall (Wasser 2002). These polysaccharides, as well as polysaccharide-protein complexes (glycoproteins), have been shown to exert their antitumor effects by influencing the immune system through the stimulation of macrophages, T lymphocytes and natural killer cells (Lindequist et al. 2005).

However other fungal high molecular weight compounds, such as flammulin, velutin and various lectins, have been shown to possess direct activity against cancer cells in vitro (Wang and $\mathrm{Ng}$ 2001, Wang et al. 2000). Recently a fungal polysaccharide derived from Cordyceps jiangxiensis was reported to exert a direct cytotoxic effect in vitro against the human gastric carcinoma cell line SGC-7901 (Xiao and Zhong 2008).

Moreover some low molecular weight fungal secondary metabolites also exhibit cytotoxicity against tumor cells. For example illudin, a tricyclic sesquiter- 
pene from Omphalotus olearius, has served as the lead structure for the semisynthetic drug irofulven, which is currently in preclinical and clinical trials due to its effects against cancer-related kinases and apoptotic activity against a range of tumors (Baekelandt 2002). Cordycepin, isolated from several Cordyceps species, has shown an apoptotic effect on various cancer cell lines (Jin et al. 2008, Wu et al. 2007) while the cytotoxicity of Lepista species has been attributed to the clitoclines (Fortin et al. 2006).

To date the majority of chemical and pharmacological investigations have focused on American, European and Asian fungal species. Macrofungi occurring in Australia are unexplored to a large extent with considerable numbers of endemic species, many of which are not formally described, possessing unknown chemical, biological and pharmacological profiles (Hawksworth 2001, May and Simpson 2001). Ethnomycological research in Australia indicates only rare use of fungi as food or internal medicine by indigenous Australians (Mallet and Grgurinovic 1996) and hence the toxicity of native species is largely unknown. Knowledge of toxicity for the few species where this has been established is derived from poisoning cases due to confusion of native mushroom species with known edible northern hemisphere species (Pauli and Foot 2005).

Here we report on the screening of extracts from 15 fungi against a panel of four cancer and two healthy cell lines to evaluate their cytotoxic potential and possible value for anti-cancer drug development. Of the 15 species 11 are considered to occur naturally in Australia (native). Seven of these native species occur only in Australia; of the other native species two, Ophiocordyceps robertsii and Cordyceps gunnii, are found in New Zealand while Hypholoma fasciculare is cosmopolitan but appears to be native to Australia. Leratiomyces ceres is native to Australia and widespread as an exotic elsewhere.

\section{MATERIALS AND METHODS}

Fungi._Fruit bodies were collected in May 2007 and 2008 at localities in the state of Victoria, Australia, and stored frozen $(-18 \mathrm{C})$ before extraction. The species chosen were mostly from genera known to possess pharmacologically active compounds, and the particular species collected were those that were available in sufficient quantity for analysis. Each sample consisted of as many fruit bodies as needed to make up the $50 \mathrm{~g}$ (except for Cordyceps cranstounii and Russula clelandii) required for analysis; all parts of the fruit body were used, including the mummified host for the vegetable caterpillars Cordyceps and Ophiocordyceps. After picking fruit bodies were lightly cleaned of soil and immediately placed in snap-lock plastic bags and stored below $15 \mathrm{C}$ until being placed in a freezer as soon as practicable after collecting.
Fungi were identified by one of the authors (TWM) from an examination of macro- and micromorphology in comparison to standard descriptions in the following floras, monographs and taxonomic treatments: Breitenbach and Kränzlin (1995) for Agaricus bitorquis and Coprinopsis atrametaria (as Coprinus atramentarius); Grgurinovic (1997) for Coprinus comatus, Hypholoma fasciculare, Leratiomyces ceres (as Hypholoma aurantiacum, syn. Stropharia aurantiaca), Lepista nuda, Omphalotus nidiformis (syn. Pleurotus nidiformis) and Psathyrella asperospora (as Lacrymaria asperospora); Miller and Hilton (1987) for Russula clelandii, interpreting that species broadly, including $R$. lenkunya as described by Grgurinovic (1997); Petersen (2008) for Xerula mundroola; and Willis (1959) for the three species of Cordyceps and Ophiocordyceps robertsii (as Cordyceps robertsii). There is no monographic treatment of Australian Tricholoma. Therefore the material is referred to as Tricholoma sp. AU2 because it differs from $T$. eucalypticum and T. austrocolossum (syn. T. australe) as described by Grgurinovic (1997) and also is not conspecific with Tricholoma sp. AU1 previously used in phytochemical studies (Ovenden et al. 2005). Names follow the draft Master Names List of Australian Fungi (RBG Melbourne, in prep) and most also are included in the Interactive Catalogue of Australian Fungi (May et al. 2010).

The status of species as native is based on usual occurrence in native vegetation or in association with native tree species, while exotic species are consistently found in gardens or other artificial habitats. The status of Lepista nuda is uncertain because it occurs in both native and exotic vegetation (Grey and Grey 2005). Voucher specimens (TABLE I) were deposited in the National Herbarium of Victoria (MEL).

Extraction and sample preparation.-Frozen fungal fruit bodies (50 g except for Cordyceps cranstounii, $38 \mathrm{gm}$ and Russula clelandii, 37g) were chopped and promptly pulverized in ethanol with a homogenizer (IKA Works Inc.: T18) and extracted successively with $100 \%$ ethanol (2 $\times 500 \mathrm{~mL}, 20-25 \mathrm{C})$, cold water $(1 \times 1000 \mathrm{~mL}, 20-25 \mathrm{C})$ and hot water $(1 \times 1000 \mathrm{~mL}, 60-80 \mathrm{C})$ for $6 \mathrm{~h}$, with vigorous stirring. Fungal material was air dried overnight to remove ethanol residues. Extracts were filtered ( $2 \times$ Whatman No. 2, $9 \mathrm{~cm}$ diam) and dried with a rotary evaporator (Buchi) or freeze dryer (Gilchrist) and stored frozen $(-18 \mathrm{C}$ ) until required. The crude extracts were resolubilize in sterile aqueous DMSO (1\% final concentration, for ethanol extracts) or MilliQ water (water extracts) and tested for cytotoxic activity at four concentrations (5.0, 0.5, 0.05 and $0.005 \mathrm{mg} / \mathrm{mL}$ ).

Cell culturing and cytotoxicity assay.-All cell lines were purchased from ATCC (Manassas, Virginia 20108). Lines were cultured in Advanced Dulbecco's modified Eagle's medium (DMEM, Gibco: 12491) supplemented with inactivated newborn calf serum (NBCS, 10\%, Gibco: 26010-074) and L-glutamine (200 mM, Gibco: 25030) at $37 \mathrm{C}$ in $5 \% \mathrm{CO}_{2}$ (Heraeus BBIS $\mathrm{CO}_{2}$ incubator). In vitro cytotoxicity was determined against normal mouse fibroblast cells (NIH/ 3T3: CRL-1658) and five human cell lines, gastric adenocarcinoma cells (AGS: CRL-1739), two mammary gland 
MYCOLOGIA

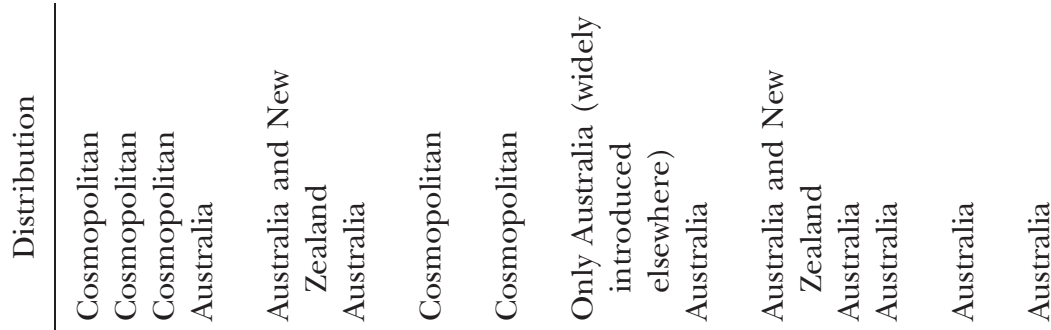

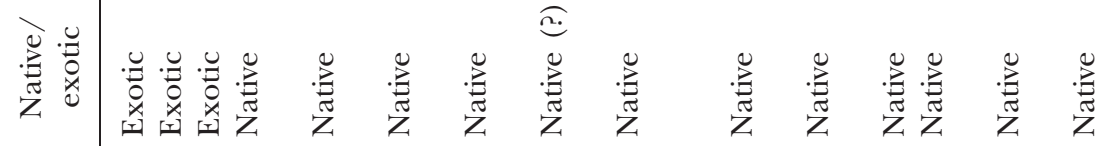

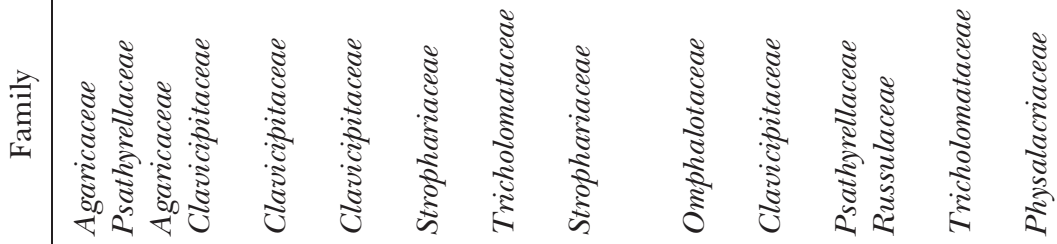

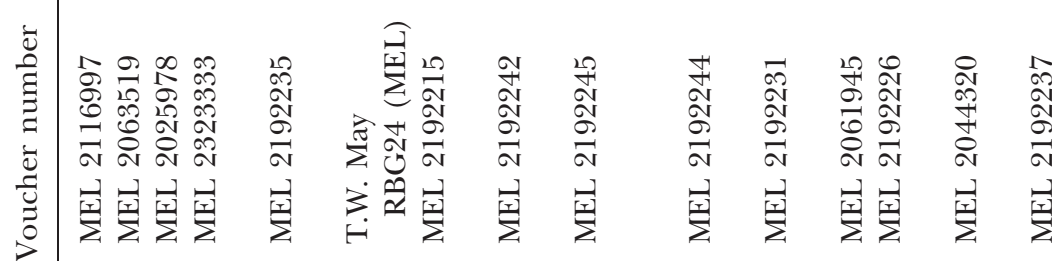

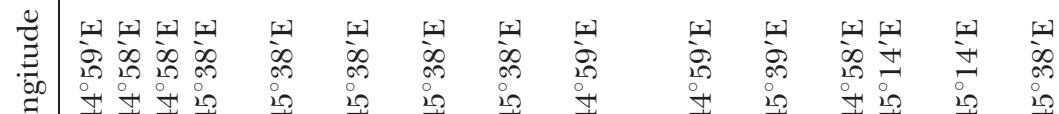

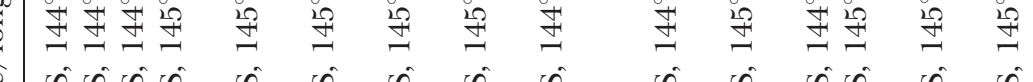

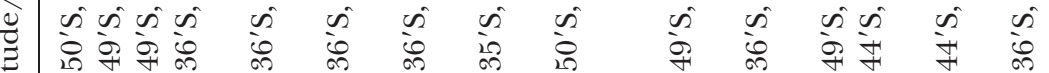

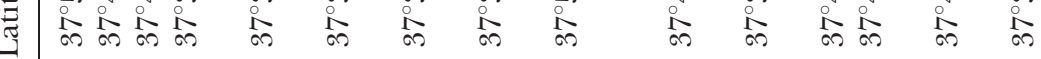

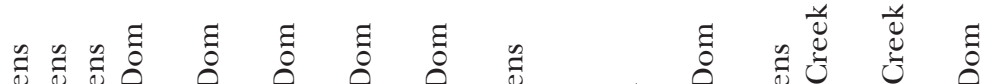

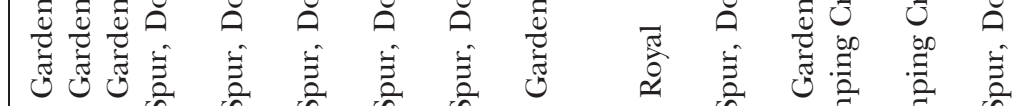

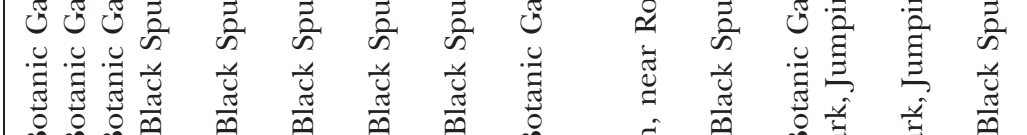

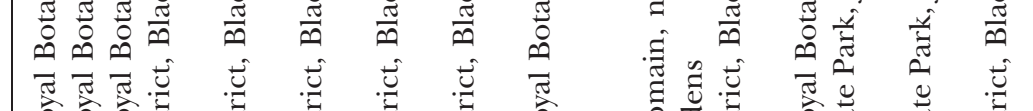

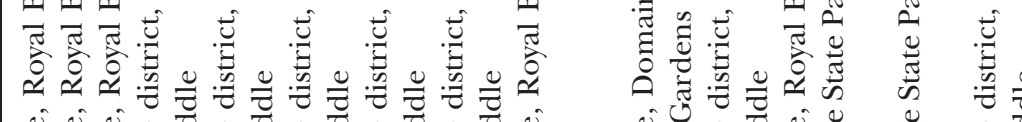

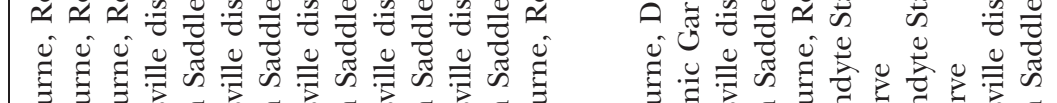

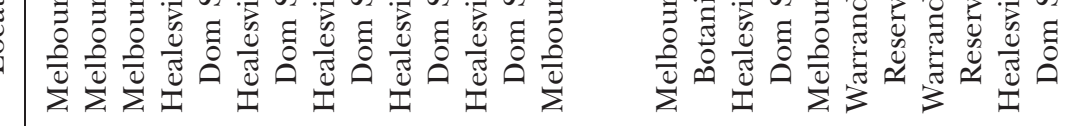

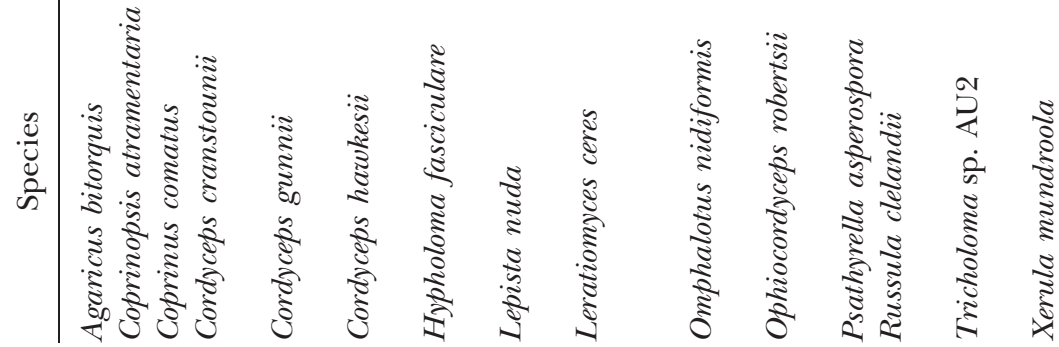


TABLE II. Yields of ethanol, cold water and hot water extracts for fungi species assayed in this study

\begin{tabular}{|c|c|c|c|c|}
\hline \multirow[b]{2}{*}{ Species } & \multirow{2}{*}{$\begin{array}{l}\text { Mass of fungi } \\
\text { extracted (g) }\end{array}$} & \multicolumn{3}{|c|}{ Mass of extract $(\mathrm{g})$ (percent yield w/w) } \\
\hline & & Ethanol (EtOH) & Cold water $(\mathrm{CW})$ & Hot water (HW) \\
\hline Agaricus bitorquis & 50 & $1.84(3.69)$ & $1.33(2.66)$ & $0.27(0.53)$ \\
\hline Coprinopsis atramentaria & 50 & $0.88(1.76)$ & $1.81(3.62)$ & $0.16(0.32)$ \\
\hline Coprinus comatus & 50 & $1.11(2.18)$ & $1.26(2.47)$ & $0.17(0.33)$ \\
\hline Cordyceps cranstouni $i^{\text {a }}$ & 38 & $2.18(5.74)$ & $0.98(2.58)$ & $0.27(0.71)$ \\
\hline Cordycpes gunnii & 50 & $1.26(2.52)$ & $7.70(15.4)$ & $0.40(0.80)$ \\
\hline Cordyceps hawkesii & 50 & $2.65(5.30)$ & $1.97(3.94)$ & $0.33(0.66)$ \\
\hline Hypholoma fasciculare & 50 & $0.95(1.90)$ & $0.83(1.66)$ & $0.22(0.45)$ \\
\hline Lepista nuda & 50 & $1.75(3.43)$ & $2.89(5.67)$ & $0.27(0.53)$ \\
\hline Leratiomyces ceres & 50 & $0.96(1.93)$ & $0.99(1.98)$ & $0.56(1.11)$ \\
\hline Omphalotus nidiformis & 50 & $4.95(9.90)$ & $1.77(3.54)$ & $2.60(5.20)$ \\
\hline Ophiocordyceps robertsii & 50 & $2.76(5.52)$ & $2.10(4.20)$ & $0.60(1.20)$ \\
\hline Psathyrella asperospora & 50 & $1.11(2.13)$ & $1.66(3.19)$ & $0.23(0.44)$ \\
\hline Russula clelandii ${ }^{\text {a }}$ & 37 & $0.76(2.05)$ & $0.96(2.59)$ & $0.15(0.41)$ \\
\hline Tricholoma sp. AU2 & 50 & $0.96(1.93)$ & $0.34(0.68)$ & $0.08(0.16)$ \\
\hline Xerula mundroola & 50 & $1.24(2.48)$ & $0.53(1.06)$ & $0.40(0.80)$ \\
\hline
\end{tabular}

${ }^{\mathrm{a}}$ For these species less than $50 \mathrm{~g}$ was available.

adenocarcinoma cells (MDA-MB-231: HTB-26, human estrogen-receptor negative (ER-); MCF7: HTB-22, human estrogen-receptor positive (ER+), healthy human epithelial kidney cells (HEK-293: CRL-1573) and colorectal adenocarcinoma cells (HT-29: HTB-38) with the MTT (3-[4,5dimethylthiazol-2-yl]-2,5-diphenyltetrazolium bromide) colorimetric assay developed by Mosmann (1983) with minor modifications as described by Popiolkiewicz et al. (2005) and as noted in the text.

Cells and medium $(150 \mu \mathrm{L})$ were seeded into 96 well plates (Nunc: 167008; MCF7 and AGS: $1.50 \times 10^{4}$; NIH/ 3T3: $0.90 \times 10^{4}$; HT-29: $3.00 \times 10^{4}$; MDA-MB-231: $1.75 \times$ 10 ${ }^{4}$; HEK-293: $2.00 \times 10^{4}$ cells/well). After $24 \mathrm{~h}$ incubation and attachment the cells were treated with different concentrations of mushroom extract $(20 \mu \mathrm{L})$ and PBS $(30 \mu \mathrm{L})$ for $48 \mathrm{~h}$. After washing and $2 \mathrm{~h}$ incubation with MTT solution $(0.5 \mathrm{mg} / \mathrm{mL}$ for cancer cell lines and $1 \mathrm{mg} /$ $\mathrm{mL}$ for healthy cell lines) cells were lysed with DMSO. The absorbance was measured after 45 min with a microplate reader (Wallac 1420 Multilabel counter, PerkinElmer) at a wavelength of $560 \mathrm{~nm}$. MilliQ-water and 1.0\% dimethylsulfoxide (DMSO) served as the negative control for water and ethanol extracts respectively, while 25\% DMSO and cycloheximide served as the positive control. The MTT assay was validated with concentrations of DMSO (0.5$25 \%)$. The results were generated from two independent experiments with each experiment performed in triplicate.

Statistical analysis._-Probit regression analysis was carried out for dose response data with LPD line software available online (http://www.ehabsoft.com/ldpline/, Bakr 2009) and was used to calculate $\mathrm{IC}_{50}$ values.

\section{RESULTS}

Fifteen Australian macrofungi, representing 13 genera, were successively extracted three times generat- ing ethanolic, cold and hot water extracts. The yields obtained for each fungal extract are provided (TABLE II).

In vitro cytotoxicity of mushroom extracts.-Extracts were screened for cytotoxic activity against healthy mouse and human kidney, as well as four human cancer cell lines (gastric, colon and breast). The $50 \%$ inhibitory concentration $\left(\mathrm{IC}_{50}\right)$ values of the ethanol and aqueous extracts of the fungi are summarized (TABLE III). In this study crude extracts with $\mathrm{IC}_{50}$ values below $1.0 \mathrm{mg} / \mathrm{mL}$ were considered significantly active and of those extracts exhibiting $\mathrm{IC}_{50}$ values below $0.1 \mathrm{mg} / \mathrm{mL}$ were deemed potently active. In the case of crude extracts that are composed of a complex mixture of metabolites, $\mathrm{IC}_{50}$ values of $0.1-1 \mathrm{mg} / \mathrm{mL}$, while somewhat high, might be indicative of cytotoxic compounds that are present at low concentrations. It is anticipated that enriching these compounds through bioassay-guided fractionation will result in significant increases in cytotoxic activity of several orders of magnitude. Approximately half of the 45 extracts tested exhibited significant cytotoxicity against at least one cell line, with no particular solvent extract (ethanol, cold or hot water) being predominantly active.

Of the panel of cell lines selected for this study our results (TABLE III) show that the normal mouse fibroblast NIH/3T3 cell line was most susceptible while the healthy human cell line HEK-293 was least susceptible to the fungi extracts. Extracts of only three fungi, Cordyceps cranstounii, Cordyceps hawkesii and Lepista nuda, exerted any cytotoxic activity against the HEK-293 cell line. 
TABLE III. Concentration at which cell growth is inhibited to $50 \%$ ( $\mathrm{IC}_{50}$ ) by the three most active fungi extracts

\begin{tabular}{|c|c|c|c|c|c|c|c|}
\hline \multirow[b]{2}{*}{ Species } & \multirow[b]{2}{*}{ Extract } & \multicolumn{5}{|c|}{ Cytotoxic activity $\left(\mathrm{IC}_{50}\right)(\mathrm{mg} / \mathrm{mL})$} & \multirow[b]{2}{*}{ AGS } \\
\hline & & $\mathrm{NIH} / 3 \mathrm{~T} 3$ & HEK-293 & HT-29 & MDA-MB-231 & MCF7 & \\
\hline \multirow[t]{3}{*}{ Cordyceps cranstounii } & $\mathrm{EtOH}$ & 0.65 & 1.72 & 2.79 & 1.65 & $>5.00$ & 3.27 \\
\hline & $\mathrm{CW}$ & 0.14 & NA & 0.41 & 0.53 & NDD & 0.41 \\
\hline & HW & 0.11 & NA & 0.12 & 0.18 & 1.88 & 0.26 \\
\hline \multirow[t]{3}{*}{ Cordyceps gunnii } & $\mathrm{EtOH}$ & 0.99 & $>5.00$ & 1.51 & 0.42 & 3.83 & 1.02 \\
\hline & CW & 0.37 & NA & 3.35 & 0.72 & $>5.00$ & 1.22 \\
\hline & HW & 0.37 & NA & 0.72 & 0.35 & $>5.00$ & 0.47 \\
\hline \multirow[t]{3}{*}{ Omphalotus nidiformis } & $\mathrm{EtOH}$ & 0.63 & NA & 0.06 & 0.04 & 1.11 & 0.06 \\
\hline & CW & 0.37 & NA & 0.71 & 0.51 & NA & 0.23 \\
\hline & HW & 0.37 & $>5.00$ & 0.49 & 0.84 & $>5.00$ & 1.04 \\
\hline Cycloheximide $^{\dagger}$ & _ & 0.0003 & & 0.0036 & 0.0004 & 0.0613 & 0.001 \\
\hline
\end{tabular}

$\mathrm{EtOH}=$ ethanol; $\mathrm{CW}=$ cold water; $\mathrm{HW}=$ hot water; NDD $=$ non dose dependent cytotoxic activity observed; $\mathrm{NA}=$ no cytotoxic activity observed at any of the concentrations evaluated; $>5.00=$ extract exhibited low cytotoxic activity at one or more concentrations evaluated; $\dagger$ cytotoxic positive control.

Selective cancer cell cytotoxic activity.-Among the 45 evaluated the cold water extract from Xerula mundroola $\left(\mathrm{IC}_{50} 0.02 \mathrm{mg} / \mathrm{mL}\right)$, all of Leratiomyces ceres $\left(\mathrm{IC}_{50} 0.15-0.83 \mathrm{mg} / \mathrm{mL}\right)$ and the ethanolic extract of Hypholoma fasciculare $\left(\mathrm{IC}_{50} 0.18 \mathrm{mg} / \mathrm{mL}\right)$ exhibited selective and significant cytotoxicity toward colon cancer (HT-29) cells but displayed low or no cytotoxicity toward all other cancer cell lines screened.

High non-selective cytotoxic activity. - The $\mathrm{IC}_{50}$ values of all Omphalotus nidiformis extracts were low for most cell lines, $0.04-1.11 \mathrm{mg} / \mathrm{mL}$, with the ethanolic extract displaying potent cytotoxicity against gastric (AGS), colon (HT-29) and estrogen-independent breast cancer (MDA-MB-231) cell lines. The cold and hot water extracts from $O$. nidiformis also were significantly active against those cell lines.

A similar pattern of significant cytotoxic activity against gastric (AGS), colon (HT-29) and estrogen independent breast cancer (MDA-MB-231) was observed for the cold and hot water extracts from C. cranstounii and the hot water extracts of Cordyceps gunnii.

Low or no cytotoxic activity.-Agaricus bitorquis, Coprinopsis atrametaria, Psathyrella asperospora, Russula clelandii, Tricholoma sp. AU2 and Xerula mundroola were the least cytotoxic species evaluated in this study; generally low or no cytotoxic effects were observed for the various extracts from these species. Of the extracts that exhibited low or no toxicity and/ or proliferative effects (results not shown) the majority corresponded to cold or hot water extracts.

\section{DISCUSSION}

Ethanol, cold and hot water extracts of predominantly native Australian macrofungi were investigated for cytotoxic activity. Successive extractions provided a rough separation of compounds on the basis of their solubility. Ethanol extracts are likely to contain both polar and nonpolar metabolites, including terpenoids (Lindequist et al. 2005), sterols, fatty acids, polypeptides and amino acids (von Usedom 2003). Conversely water extracts are likely to contain water-soluble compounds including carbohydrates such as polysaccharides and small amounts of proteins and minerals (von Usedom 2003). Moreover many of the traditional preparations of medicinal mushrooms employ either hot or cold aqueous preparations and it has been suggested that a hot water extract from Inonotus obliquus might suppress cellular proliferation in human stomach cancer (Watanabe 2004). Therefore hot water extracts also were evaluated in this study. Gastric, colorectal and two breast cancer cell lines were selected for the test panel because they represent some of the most prevalent types of cancer (World Health Organization 2008). Of interest all species showed low or no cytotoxic activity against human healthy cells and some had significant (Omphalotus nidiformis, Cordyceps. cranstounii and Cordyceps gunnii) and selective (Xerula mundroola, Leratiomyces ceres, Hypholoma. fasciculare) activity against cancer cells.

In our study $O$. nidiformis extracts overall were the most cytotoxic extracts. Species of Omphalotus contain several types of illudins, a class of oxygenated sesquiterpenes that possess antitumor, cytotoxic and antibiotic activity (Kelner et al. 1990). The toxicity of $O$. nidiformis, colloquially known as ghost fungus due to luminescence, is presumably due to the illudins, as is the case for other species in the genus (Benjamin 1995). In common with northern hemisphere species of the genus $O$. nidiformis contains illudins such as $\mathrm{M}$ and S (Kirchmair et al. 1999) but also three novel 
illudins (F, G and H) (Burgess et al. 1999). $O$. nidiformis is widespread in temperate Australia (Grey and Grey 2005), and there have been a number of human poisonings in Australia due to $O$. nidiformis being confused with edible Pleurotus species (Hender et al. 2000). Given that illudins are extractable with non-polar solvents and the highest cytotoxic activity was detected in ethanolic extracts, we presume that the illudins are responsible, or at least contribute, to the activity. The mushroom can be grown in pure culture (Burgess et al. 1999) and it therefore will be practicable to carry out further studies to establish whether the compounds responsible for the activity are indeed illudins and whether they are those shared with other species or are possible unique to $O$. nidiformis.

Illudins also have been reported from Coprinus comatus (Gonzalez del Val et al. 2003). Not surprising therefore studies have shown anti-proliferative effects of ethanol and ethyl acetate extracts against prostate cancer cells (LNCaP) (Zaidman et al. 2008) and of ethyl acetate extracts against ovarian cancer cells (ES2) (Rouhana-Toubi et al. 2009). A cold water extract also showed activity against estrogen-dependent and independent breast cancer cells ( $\mathrm{Gu}$ and Leonard 2006). In contrast we observed activity for the ethanolic instead of the water extract of $C$. comatus, which might indicate that the cytotoxic compounds were solubilized in our initial ethanol extraction and could be attributed to the illudins.

Given that illudins are known from Coprinopsis atramentaria (as Coprinus atramentarius) (Lee et al. 1996), it was surprising that none of the extracts from the Australian specimens of this species exhibited significant cytotoxicity. Coprinus and Coprinopsis species examined in this study are thought to have been introduced to Australia. C. atramentaria has a wide distribution globally (May et al. 2010), and perhaps different growing conditions throughout its range contribute to different compositions of constituents as might different genotypes.

Extracts from Australian C. cranstounii and $C$. gunnii exhibited significant cytotoxic effects against a variety of cancer cell lines. In contrast the remaining two species of Cordyceps sensu lato (C. hawkesii and Ophiocordyceps roberstii) showed significantly less cytotoxic potential. Cytotoxic activity has not been reported for any of the four native Cordyceps and Ophiocordyceps species examined in this study, however species of Cordyceps sensu lato are used in traditional Chinese medicine and consequently the chemistry and pharmacology of the medicinal Cordyceps militaris and Ophiocordyceps sinensis (syn. Cordyceps sinensis) have been examined extensively, with more than 60 cytotoxic activity reports of species from Cordyceps sensu lato.
Genus Cordyceps in the broad sense (sensu lato) contains entomopathogenic fungi that parasitize a range of arthropods and fungi, including caterpillar larvae. A number of segregate genera from Cordyceps sensu lato have been recognized (Sung et al. 2007), although not all species have been placed in this new classification yet.

Liu et al. (2002) considered C. hawkesii to be a synonym of $C$. gunnii, based on similarities of ITS sequences among Chinese material under these names. However reports of C. gunnii, C. hawkesii and O. robertsii (as C. robertsii) from China (Liu et al. 2002) appear to be misidentifications because the provided ITS sequences of Chinese collections have low BLAST matches against those of Australian collections. For example AJ309344 (C. gunnii, Australia) has only 86\% match against AJ309340 (C. gunnii, China), whereas Chinese isolates (variously identified as C. gunnii, $C$. hawkesii or Paecilomyces anamorphs of the two) have matches of $94 \%$ or higher. Until sequence data are available for a range of Australian collections we prefer to recognize $C$. hawkesii as distinct from $C$. gunnii based on morphological characters, in particular the well demarcated fertile portion of the club (Grey and Grey 2005, Willis 1959).

This study is the first cytotoxic evaluation of the Australian native mushrooms C. cranstounii, C. gunnii, C. hawkesii, O. robertsii, Psathyrella asperospora, L. ceres, Tricholoma sp. AU2, X. mundroola and Russula clelandii and has confirmed the in vitro cytotoxic effects for $O$. nidiformis against various cancer cell lines. We furthermore showed that extracts from the cosmopolitan species C. atramentaria collected in Australia do not exert significant cytotoxic effects against the cell lines tested. We also identified a marked difference between the cytotoxic profile of Australian material of C. hawkesii and C. gunnii that supports their treatment as distinct species.

Our study provides a first comprehensive evaluation of the cytotoxicity of various Australian fungi species and forms an important basis for the isolation and structural elucidation of cytotoxic compounds from these species in the future.

\section{ACKNOWLEDGMENTS}

This work was financially supported by the Australian National Institute of Complementary Medicine. Fungi from national parks were collected under permit from the Department of Sustainability and Environment, Victoria, Australia.

\section{LITERATURE CITED}

Baekelandt M. 2002. Irofulven MGI Pharma. Curr Opin Investig Dr 3:1517-1526. 
Bakr E. 2009. LDP Line software. Available from: http:// www.ehabsoft.com/ldpline/

Benjamin DR. 1995. Mushrooms: poisons and panaceas. New York: W.H. Freeman \& Co. 422 p.

Breitenbach J, Kränzlin F. 1995. Fungi of Switzerland. Vol. 4, Agarics 2. Lucerne, 368 p.

Burgess ML, Zhang YL, Barrow KD. 1999. Characterization of new illudanes, illudins $\mathrm{F}, \mathrm{G}$, and $\mathrm{H}$ from the Basidiomycete Omphalotus nidiformis. J Natl Prod 62: 1542-1544, doi:10.1021/np990247d

Dong P. 2001. Peoples Republic of China. A medicine for the treatment of malignant tumor. China patent $\mathrm{CN}$ 1307892 .

Fortin H, Tomasi S, Delcros J-G, Bansard J-Y, Boustie J. 2006. In vivo antitumor activity of clitocine, an exocyclic amino nucleoside isolated from Lepista inversa. ChemMedChem 1:189-196, doi:10.1002/cmdc.200500029

Gonzalez del Val A, Platas G, Arenal F, Orihuela JC, Garcia M, Hernandez P, Royo I, de Pedro N, Silver LL, Young K, Vicente MF, Pelaez F. 2003. Novel illudins from Coprinopsis episcopalis (syn. Coprinus episcopalis) and the distribution of illudin-like compounds among filamentous fungi. Mycol Res 107:1201-1209, doi:10.1017/S0953756203008487

Grey P, Grey E. 2005. Fungi down under: the fungimap guide to Australian fungi. Australia: Fungimap. 146 p.

Grgurinovic CA. 1997. Larger fungi of south Australia. Adelaide: The Botanic Gardens of Adelaide and State Herbarium and The Flora and Fauna of South Australia Handbooks Committee. 725 p.

$\mathrm{Gu}$ Y-H, Leonard J. 2006. In vitro effects on proliferation, apoptosis and colony inhibition in ER-dependent and ER-independent human breast cancer cells by selected mushroom species. Oncol Rep 15:417-423.

Hawksworth DL. 2001. Mushrooms: the extent of the unexplored potential. Int J Med Mushr 3:333-340.

Hender E, May T, Beulke S. 2000. Poisoning due to eating fungi in Victoria. Aust Fam Physician 29:1000-1004.

Huang Z. 2007. Peoples Republic of China. Novel antitumor pharmaceutical composition comprising traditional Chinese medicine extracts. China patent CN 101049336.

Jin C-Y, Kim G-Y, Choi Yung H. 2008. Induction of apoptosis by aqueous extract of Cordyceps militaris through activation of caspases and inactivation of Akt in human breast cancer MDA-MB-231 cells. J Microbiol Biotechn 18:1997-2003.

Kelner MJ, McMorris TC, Taetle R. 1990. Preclinical evaluation of illudins as anticancer agents: basis for selective cytotoxicity. J Natl Cancer Inst 82:1562-1565, doi:10.1093/jnci/82.19.1562

Kim HJ, Chang WK, Kim MK, Lee SS, Choi BY. 2002. Dietary factors and gastric cancer in Korea: a case-control study. Int J Cancer, 531-535, doi:10.1002/ijc.10111

Kirchmair M, Poder R, Huber CG. 1999. Identification of illudins in Omphalotus nidiformis and Omphalotus olivascens var. indigo by column liquid chromatography-atmospheric pressure chemical ionization tandem mass spectrometry. J Chromatogr A 832:247-252, doi:10.1016/S0021-9673(98)00892-9
Lee I-K, Jeong C-Y, Cho S-M, Yun G-S, Kim Y-S, Yu S-H, Koshino H, Yoo I-D. 1996. Illudins C2 and C3, new illudin $\mathrm{C}$ derivatives from Coprinus atramentarius ASI20013. J Antibiot (Tokyo) 49:821-822.

Lindequist U, Niedermeyer Timo HJ, Julich W-D. 2005. The pharmacological potential of mushrooms. Evid Based Compl Alt Med 2:285-299, doi:10.1093/ecam/neh107

Liu Z-Y, Liang Z-Q, Liu A-Y, Yao Y-J, Hyde KD, Yu Z-N. 2002. Molecular evidence for teleomorph-anamorph connections in Cordyceps based on ITS-5.8S rDNA sequences. Mycol Res 106:1100-1108, doi:10.1017/ S0953756202006378

Mallet K, Grgurinovic C. 1996. Fungi of Australia. Vol. 1B. Introduction: fungi in the Environment. Melbourne: ABRS/CSIRO Publishing. 405 p.

May TW, Milne J, Wood AE, Shingles S, Jones RH, Neish P. 2010. Interactive catalogue of Australian Fungi. Version 2.0. Australian Biological Resources Study, Canberra/ Royal Botanic Gardens Melbourne. [http://www.rbg. vic.gov.au/dbpages/cat/index.php/fungicatalogue]

—_, Simpson J. 2001. Preface to biodiversity and biogeography of Australian fungi. Aust Syst Bot 14:iiii, doi:10.1071/SBv14n3_PR

Miller OK, Hilton RN. 1987. New and interesting agarics from Western Australia. Sydowia 39:126-137.

Mosmann T. 1983. Rapid colorimetric assay for cellular growth and survival: Application to proliferation and cytotoxicity assays. J Immunol Methods 65:55-63, doi:10.1016/0022-1759(83)90303-4

Ovenden S, Yu J, Bernays J, Wan SS, Christophidis L, Sberna G, Murray Tait R, Wildman H, Lebeller D, Platel D, May T, Meurer-Grimes B. 2005. Trichomycines A and B: antibacterial triterpenes from the new species of Tricholoma sp. AU1. J Natl Prod 68:409-412, doi:10.1021/np049747j

Pauli JL, Foot CL. 2005. Fatal muscarinic syndrome after eating wild mushrooms. Med J Aust 182:294-295.

Petersen RH. 2008. The genus Xerula (Agaricales; Fungi) in Australia and New Zealand Nova Hedwig 87:1-67.

Popiolkiewicz J, Polkowski K, Skierski JS, Mazurek AP. 2005. In vitro toxicity evaluation in the development of new anticancer drugs-genistein glycosides. Cancer Lett 229: 67-75, doi:10.1016/j.canlet.2005.01.014

Rouhana-Toubi A, Wasser SP, Fares F. 2009. Ethyl acetate extracts of submerged cultured mycelium of higher Basidiomcetes mushrooms inhibit human ovarian cancer cell growth. Int J Med Mushr 11:29-37, doi:10.1615/IntJMedMushr.v11.i1.40

Sung G-H, Hywel-Jones NL, Sung J-M, Luangsa-ard JJ, Shrestha B, Spatafora JW. 2007. Phylogenetic classification of Cordyceps and the clavicipitaceous fungi. Stud Mycol 57:5-59, doi:10.3114/sim.2007.57.01

von Usedom A. 2003. Stoffe, Materie, Periodensystem, Chemische Bindung. Munchen: Mentor-Verl. 72 p.

Wang H, Gao J, Ng TB. 2000. A new lectin with highly potent antihepatoma and antisarcoma activities from the oyster mushroom Pleurotus Ostreatus. Biochem Biophys Res Commun 275:810-816, doi:10.1006/ bbrc.2000.3373

— $\mathrm{Ng}$ TB. 2001. Isolation and characterization of 
velutin, a novel low-molecular-weight ribosome-inactivating protein from winter mushroom (Flammulina velutipes) fruiting bodies. Life Sci 68:2151-2158, doi:10.1016/S0024-3205(01)01023-2

Wasser SP. 2002. Medicinal mushrooms as a source of antitumor and immunomodulating polysaccharides. Appl Microbiol Biotechnol 60:258-274, doi:10.1007/ s00253-002-1076-7

— Weis AL. 1999. Medicinal properties of substances occurring in higher basidiomycetes mushrooms: current perspectives (review). Int J Med Mushr 1:31-62.

Watanabe S. 2004. Proceedings of the 3rd International Conference on Food Factors. Amsterdam: IOS Press. 800 p.

Willis JH. 1959. Australian species of the fungal genus Cordyceps (Fr.) Link. Muelleria 1:67-89.

World Health Organization. 2008. World cancer report 2008. Lyon, France: International Agency for Research on Cancer, Available at www.iarc.fr/en/publications/ pdfs-online/wcr/2008/wcr_2008.pdf

Wu W-C, Hsiao J-R, Lian Y-Y, Lin C-Y, Huang B-M. 2007. The apoptotic effect of cordycepin on human OEC-M1 oral cancer cell line. Cancer Chemother Pharmacol 60:103111, doi:10.1007/s00280-006-0354-y

Xiao J-h, Zhong J-j. 2008. Inhibitory effect of polysaccharides produced by medicinal macrofungus Cordyceps jiangxiensis on cancer cells via apoptotic pathway and cell cycle arrest. J Food Agric Environ 6:61-67.

Zaidman BZ, Wasser SP, Nevo E, Mahajna J. 2008. Coprinus comatus and Ganoderma lucidum interfere with androgen receptor function of LNCaP prostate cancer cells. Mol Biol Rep 35:107-117, doi:10.1007/s11033-0079059-5

Zhang H. 2002. Peoples Republic of China. An oral Chinese medicinal preparation for the treatment of cerebroma and hydrocephalu. China patent CN 1352982.

, Huang J, Xie X, Holman C. 2009. Dietary intakes of mushrooms and green tea combine to reduce the risk of breast cancer in Chinese women. Int J Cancer 124: 1404-1408, doi:10.1002/ijc.24047

Zhu S, Wei Z. 2000. Peoples Republic of China. An anticancer chinese medicine and its preparation method. China patent CN 1247745. 